\title{
A gestão democrática em servidores do IFRN: Um estudo das
}

\section{representações sociais}

\author{
Ionara Dantas Estevam \\ Doutora em Psicologia Social pela Universidade Federal da Paraíba (UFPB). Professora e \\ pesquisadora na Universidade Potiguar (UnP)-Laureate International Universities. Professora na \\ Faculdade Maurício de Nassau (RN). E-mail: ionaradantas@gmail.com (Brasil) \\ Paula Francinete Araújo Batista \\ Mestra em Psicologia Organizacional e do Trabalho pela Universidade Potiguar (UnP). \\ E-mail: paula.araujo@ifrn.edu.br (Brasil)
}

\section{Nilton Soares Formiga}

Doutor em Psicologia Social pela Universidade Federal da Paraíba (UFPB). Professor e pesquisador na Universidade Potiguar (UnP)-Laureate International Universities. E-mail: nsformiga@yahoo.com

(Brasil)

\section{RESUMO}

O processo de gestão educacional do Instituto Federal de Educação, Ciência e Tecnologia do Rio Grande do Norte aparece como gestão democrática, crítica e dialética, no qual o poder é descentralizado e as decisões são tomadas por meio dos conselhos e da participação da comunidade escolar. Assim, neste estudo, a concepção de gestão democrática-participativa foi adotada a partir de sua relação com a Teoria das Representações Sociais, pois tal intersecção possibilita o estudo elaborado e compartilhado do senso comum, uma vez que está sempre pautada na inter-relação entre os atores sociais e o seu entorno. Sendo assim, este estudo tem como objetivo analisar as representações dos servidores em relação ao processo de gestão democrática no âmbito do Instituto Federal de Educação, Ciência e Tecnologia do Rio Grande do Norte. Trata-se de uma pesquisa qualitativa de cunho exploratório-descritivo, realizada em três campi do IFRN, com 130 servidores, sendo estes do sexo masculino e feminino e com idade acima de 21 anos. Utilizouse como instrumento para a coleta de dados uma entrevista estruturada. Os dados coletados foram submetidos à Técnica de Análise de Conteúdo de Bardin. Os resultados apontam para a necessidade de materialização do que está escrito nos documentos oficiais e o desenvolvimento da concepção de gestão democrática dentro da instituição. As dificuldades encontradas têm relação com vários fatores, tais como: falta de participação dos servidores, conhecimento superficial dos documentos oficiais, teoria sem prática, dificuldade de usufruir das ações macro da instituição, entre outras.

Palavras-chave: Gestão. Democracia. Representação social. Servidores públicos. 


\title{
The democratic management in workers from IFRN: A study of social representations
}

\begin{abstract}
The process of educational management of IFRN is observed as democratic, critic and dialectic, where the power is decentralized and the decisions are made through councils and the participation of the scholar community. For this study, the conception of management adopted was democratic-participative, seeking to relate with the Theory of Social Representations, because it enables the elaborated study and the shared common sense, once is always focused on inter-relation among the social actors and its surroundings. This study has as goal to the representation analysis of the employees in the process of democratic management in the IFRN. It is an exploratory-descriptive research, performed in three Campi from IFRN, with 130 employees, males and females above 21 years old. A structured interview was used as instrument, the collected data were submitted to Bardin's Content analysis Technique. The results point to the need of materialization of what is written on the official documents and the development of the conception of democratic management inside the institution. The difficulties found are related to various factors, such as: lack of employees' participation, shallow knowledge of the official documents, theory without practice, difficulty to enjoy the institution macro actions.
\end{abstract}

Keywords: Management. Democracy. Social representation. Public employees.

\section{Como referenciar em APA:}

Estevam, I. D., Batista, P. F. A. \& Formiga, N. S. (2018). A gestão democrática em servidores do IFRN: um estudo das representações sociais. R.G.Secr.,GESEC, 9(2). DOI:

\section{Como referenciar em ABNT:}

ESTEVAM, I. D.; BATISTA, P. F. A; FORMIGA, N. S. A gestão democrática em servidores do IFRN: um estudo das representações sociais. R.G.Secr.,GESEC, v. 9, n. 2, 2018. DOI:
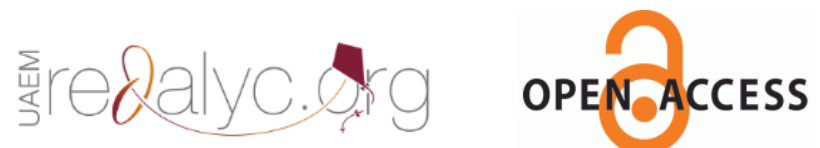


\section{Introdução}

O Instituto Federal de Educação, Ciência e Tecnologia do Rio Grande do Norte (IFRN) encontra-se representado por 21 campi e uma reitoria, tendo na sua função social o compromisso de ofertar educação profissional e tecnológica de qualidade, articulando a ciência e o trabalho, a formação humana integral, valorizando os aspectos culturais do espaço onde estiver inserido, com princípios ancorados na justiça social, gestão democrática, integração e verticalização do ensino (IFRN, 2012).

Esse enfrentamento vem sendo superado por meio de um planejamento sistêmico e de uma proposta político-pedagógica que condiz com a nova realidade do IFRN, a partir dos documentos: Projeto Político Pedagógico (PPP), Plano de Desenvolvimento Institucional (PDI), dentre outros, visto a sua dimensão multicampi (IFRN, 2012). Assim, todo o processo de gestão educacional do IFRN aparece como gestão democrática, crítica e dialética, no qual o poder é descentralizado e as decisões são tomadas a partir dos conselhos e da participação da comunidade escolar.

Nesse contexto de participação, Bordenave (1983) apresenta semelhante concepção, porém, em um sentido mais amplo, na qual o cidadão que participa do processo de gestão deve contribuir com as decisões de forma crítica e reflexiva, tomando para si a responsabilidade dos resultados no processo do qual fez parte.

Segundo Moscovici (1996), a participação dos indivíduos não os coloca apenas como processadores de poder e informações, mas partícipes ativos que produzem e comunicam incessantemente suas próprias representações e soluções específicas para as questões que colocam a si mesmos, e, assim, a teia das relações entre os indivíduos vai sendo construída e desconstruída de acordo com as necessidades que se apresentam, seja individualmente ou coletivamente. No IFRN, essa participação aparece como um dos pilares de sustentação nesse novo formato de estrutura administrativa.

A história da educação profissional brasileira apresenta diversos momentos de crescimento e retrocesso ao longo dos seus 111 anos. A partir desses caminhos percorridos, o IFRN traçou sua trajetória sob vários contextos sociais. Segundo Fernandes (2015), esse trajeto pode ser compreendido sob a ótica da história na qual foi construída, retratada a partir dos momentos históricos e políticos apresentados pelos documentos, a saber: Decreto $\mathrm{n}^{\circ} \mathbf{7 . 5 6 6 / 1 9 1 0}$ (Criação da Escola de Aprendizes e Artífices), Decreto nº 13.064/1918 (Marco Regulatório da Escola de Aprendizes e Artífices), Lei no 11.892/2008 (Criação dos Institutos Federais), 
Resolução $n^{\text {o }}$ 38/2012/IFRN (Projeto Político Pedagógico-PPP), Resolução $n^{\circ}$ 15/2010/Consup/IFRN (Regimento Geral do IFRN), Resolução n 29/2014/Consup/IFRN (Plano de Desenvolvimento Institucional- PDI).

A formação humana integral defendida pelo Projeto Político Pedagógico - PPP do IFRN, corrobora com o pensamento de Gramsci (2001), que defendia a escola unitária para todos. O autor compreendia que a escola é um meio para emancipar os sujeitos e transformar a realidade do meio social, oportunizando a construção de uma nova identidade e por conseguinte, gerando uma reorganização geográfica que se apresentou em função da expansão da Rede Federal de Ensino, tendo como objetivo uma educação que proporcione tanto novos significados ao ensino e à aprendizagem, quanto um melhor desenvolvimento social na vida daqueles que estejam inseridos na própria instituição de ensino.

Para Gatti (2002), a história das Instituições educativas está ligada aos elementos que formam a sua identidade, mesmo que ela, ao longo do tempo, tenha se transformado, sendo que isso se apresenta como um ciclo em todas as esferas seja física, pedagógica ou de gestão. Com a proposta de interiorização do IFRN, novos desafios surgiram, tornando necessário um novo desenho institucional que, no contexto atual político-educacional e organizacional, focasse no funcionamento institucional, articulando ensino, pesquisa e extensão e que levasse em consideração os arranjos produtivos locais e uma gestão pública inovadora frente as novas exigências pedagógicas (Santos \& Prado, 2014; Gracindo, 2009; Dourado, 2007).

\section{Gestão democrática}

A escola contemporânea, em geral, busca manter as relações sociais, discutindo nas suas instâncias consultivas e deliberativas, sobre as suas demandas e procurando socializar o saber, a ciência e as demandas produzidas socialmente. Tal condição tem levado a ação educativa envolvendo uma democratização das escolas públicas e demonstrado um avanço significativo, embora ainda seja necessário um maior envolvimento da comunidade escolar.

Assim, a gestão democrática pode ser entendida como um espaço que descentraliza o poder das instituições e que, na concepção de Souza (2009), é compreendida como um processo político no qual as pessoas que atuam sobre a escola identificam problemas, discutem, deliberam, planejam, encaminha e acompanham. Esses processos têm como base a participação efetiva de todos os segmentos da comunidade escolar, isto quer dizer que a gestão da escola pode ser entendida pretensamente como um processo democrático no qual a democracia é um 
princípio. É certo que essas ideias não expressam a realidade das escolas públicas, mas um objetivo a ser alcançado.

A Constituição Federal de 1988, dentre outros marcos legais vigentes no Brasil, orientam que a gestão democrática deve ser organizada a partir da participação coletiva. Considerando essa perspectiva, para Luck (2006), a gestão democrática, enquanto promotora da melhoria da qualidade educacional de forma participativa, autorreflexiva contextual/plural, processual e transformadora, oferece oportunidade aos indivíduos para definir e se orientar por meio dos valores, objetivos e prioridades exigidas em um processo democrático na escola. Esse processo se torna mais envolvente por se tratar da autonomia das instituições.

Para implantar a gestão democrática em qualquer instituição de ensino faz-se necessário representar, antes de tudo, a capacidade de planejar, executar e avaliar, para que o autoritarismo e as posturas inadequadas não prevaleçam, sendo necessário, ainda, um conhecimento profundo dos problemas educacionais existentes, uma vez que o processo de democratização está associado aos mecanismos legais e institucionais mais complexos que contemple a participação dialética alunos-servidores-comunidade (Macedo, 2000).

Por ser complexa, a democratização do ensino exige uma compreensão mais profunda dos problemas que o circundam. Esse enfoque nos leva a analisar a concepção, a execução, o pensar, o fazer teórico e as práticas que são discutidas dentro das escolas, em especial nas escolas públicas. Isso talvez implique intervenções pessoais nas administrações e usufruto, o que possivelmente trará a possibilidade de um novo fazer dentro e fora das escolas (Veiga, 1997).

Nesse sentido, faz-se necessário destacar a importância da gestão escolar na busca constante em conseguir a participação de todos: Conselho Escolar, alunos, servidores e a comunidade em geral, buscando o fortalecimento da escola.

Assim, compete à gestão escolar estabelecer o direcionamento e a mobilização capazes de sustentar e dinamizar a cultura das escolas, de modo que sejam orientadas para resultados, isto é, um modo de ser e de fazer caracterizado por ações conjuntas, associadas e articuladas. Sem esse enfoque os esforços e gastos são dispendidos sem muitos resultados, que é o que tem acontecido na educação brasileira, uma vez que se tem adotado, até recentemente, a prática de buscar soluções tópicas, localizadas e restritas, quando, de fato, os problemas da educação e da gestão escolar são globais e estão inter-relacionados; pois, de acordo com Luck (2006), o processo de gestão escolar democrático pode ser compartilhado por todos. 
A literatura sobre a gestão participativa reconhece que a vida organizacional contemporânea é altamente complexa, assim como os seus problemas. No final da década de 1970, os educadores e pesquisadores de todo o mundo começaram a prestar maior atenção ao impacto da gestão participativa na eficácia das escolas como organização, ao observar que não é possível para o diretor solucionar sozinho todos os problemas e questões relativas à sua escola, passaram a adotar a abordagem participativa fundada no princípio de que, para a organização ter sucesso, é necessário que os diretores busquem os conhecimentos específicos e as experiências dos seus companheiros de trabalho.

Lima (2000) afirma que a democratização da gestão escolar deve focalizar as intervenções de forma democrática e que deve ser exercida pelos autores educativos de forma substancial em ações políticas e administrativas, a partir de um contexto organizacional de poder de decisão dentro das estruturas democráticas existentes no contexto escolar. Esse pensamento consiste na afirmação em que a gestão democrática é um ato político, precisa de articulação e, antes de tudo, de ações voltadas para a educação política.

Nesse contexto, a gestão democrática pode ser entendida como um fenômeno de governo, político, que dá sustentação a todo o processo democrático e suas ações são sempre voltadas para uma educação que busca alternativas para o cotidiano escolar, fortalecendo as relações de poder ali existentes.

Assim, a escola torna-se maior que seu interior, indo muito além dos seus muros, sendo um lugar de convivência e tolerância, pois, de acordo com Paro $(2012 ; 11)$, “o ser humano só vive se conviver com os outros". Ou seja, pensar a democracia é pensar em várias possibilidades, pois se assim não acontecer, a democracia se torna estática. Nesse sentido, a gestão democrática da educação requer uma postura mais ampla nas estruturas organizacionais e o Instituto Federal de Educação, Ciência e Tecnologia do Rio Grande do Norte busca assegurar por meio da sua legislação a gestão democrática como concepção.

Portanto, para o IFRN, a gestão democrática deve acontecer por meio de acompanhamento sistematizado para garantir a implementação de ações que venham a melhorar a participação de todos, no planejamento, na execução ou no usufruto das dimensões anteriores.

Para contextualização da gestão democrática em uma instituição de ensino, faz-se necessário praticar, incisiva e cautelosamente, cada um dos direcionamentos do componente "perfil da gestão". Defender essa concepção implica avançar de uma visão de estrutura piramidal e hierarquizada para uma proposição de esboço em espiral, preconizada pela interrelação entre os atores sociais envolvidos, aproximando-se, portanto, de uma perspectiva mais 
democrática. A partir dessa concepção é que uma gestão política, econômica e organizacional (por exemplo, descentralização dos poderes, redistribuição das finanças, criação de conselhos e colegiados, integração de ações, dinamização da organização dos setores, bem como, incentivo na participação ativa da comunidade escolar em geral) é apresentada e estabelecida quanto meta da manutenção da democracia escolar (Brasil, 1988; 1996).

Sendo assim, a construção individual do sujeito com a realidade social (leia-se, escolar) situa-se entre o universo e o particular, não sendo possível existir polarização, e as mediações sociais aparecem como estratégias para gerar formas que buscam entender e enfrentar a diversidade social na qual os sujeitos estão inseridos e como os mesmos interagem entre si (Jovchelivitch, 2001). Para tal condição, a teoria das representações sociais viabiliza, de forma metodológica e teórica, elementos comunicacionais que são capazes de fomentar no sujeito e no grupo a tomada de decisão com base na construção de como a realidade é representada na dinâmica individuo-sociedade.

\section{Representação social: uma perspectiva de análise}

Nas últimas décadas a Teoria Representação Social (TRS) vem se destacando com muita frequência em áreas do conhecimento que buscam entender o processo vivido pelos indivíduos. Jodelet (2001) afirma que a representação social vem, historicamente, despertando interesse das outras ciências humanas, como a História, a Antropologia e a Sociologia, sendo um processo no qual os indivíduos em interação social conseguem construir suas explicações sobre o meio social.

Ainda segundo Jodelet (2001, p. 22), a representação social “é um conhecimento socialmente elaborado e partilhado, com um objetivo prático, e que contribui para a construção de uma realidade comum a um conjunto social", pela afirmação, observa-se que as representações sociais têm na sua essência o estudo dos conhecimentos elaborados, fazendo parte das crenças e vivências de um grupo específico.

Para Moscovici (1996), ao estudar as representações sociais estamos assegurando uma compreensão do ser humano. Isso se dá pela possibilidade de se compreender como o sujeito se comporta em sociedade e em que circunstâncias sociais interagem.

Por buscar explicar a construção e a transformação dos saberes populares é que a teoria das representações sociais tenta explicar esse fenômeno. Tais saberes, de forma geral, são produzidos no cotidiano, interpretando comportamentos individuais e coletivos. É a partir dessa 
realidade que se elaboram as ideias propagadas de acordo com os saberes, sendo possível construir uma rede de comunicação e de formar um grande suporte para o entendimento das representações sociais (França, 2004).

Diante dessa realidade é possível afirmar que as representações sociais têm como função a construção de comportamentos, estabelecendo a comunicação entre os indivíduos e o grupo social do qual faz parte e produzindo interações interpessoais, constituindo-se como forma de conhecimento que são compartilhadas socialmente, sendo o sujeito ativo e construtor (Moscovici, 1978).

Nesse sentido, Moscovici (1996) defende dois mundos: o da experiência individual, onde os comportamentos e as percepções são entendidos como resultado de um processo íntimo, muitas vezes de natureza fisiológica e, no outro mundo, o dos grupos, onde as coisas acontecem a partir das relações entre as pessoas e tudo pode ser explicado em função da relação entre os sujeitos, seja por meio das estruturas existentes, ou da troca de poder.

De acordo com Moscovici (1978), duas formas de representação são possíveis: a cognitiva e a comunidade; a primeira diz respeito ao sistema de valores que orienta a interação do indivíduo com o seu meio social e material, o segundo tem sua base nas trocas, na história individual e coletiva. Dessa forma, ainda conforme o autor, a Teoria das Representações Sociais, no que diz respeito à construção dessas representações, figura como uma forma de conhecimento elaborada e partilhada, que posteriormente, apresenta dois processos que atuam comumente: o de objetivação e o de ancoragem. Esses processos são importantes, uma vez que explicam as representações sociais constituídas de acordo com a construção do pensamento de um grupo.

A objetivação, compreendida também, com uma espécie de mecanismo simbólico das representações sociais, transforma um conceito em uma imagem, é um processo de informação privilegiada em relação a outras, possibilitando transformar o que é abstrato, complexo, em algo concreto (Trindade, Santos \& Almeida, 2014).

Diante das contribuições de Moscovici (2003), o processo de ancoragem é apresentado como a possibilidade de caracterizar objetos e pessoas que se enquadram em categorias. "Ancorar é dar nome a alguma coisa. Coisas que não são classificadas e as que não possuem nomes são estranhas" (p. 61). Nessa perspectiva, a ancoragem é entendida com a transformação de algo estranho em algo familiar ou comum.

Nessa direção, Moscovici (2003) afirma que a representação social apresenta duas faces independentes: a face icônica, que é a representação nítida de um objeto e a face simbólica que 
iguala toda imagem a uma ideia e toda ideia a uma imagem. "Ancorar é classificar e dar nome a alguma coisa, torná-la familiar, pois coisas que não são nomeadas ou classificadas, são estranhas, não existem [...]. Objetivação é transformar algo abstrato em algo quase concreto, transferir o que está na mente em algo que existe no mundo físico” (p. 81). Assim, ancoragem e objetivação são formas de organizar a memória, sendo a primeira responsável por manter a memória em movimento tirando e colocando tudo que ela conseguir rotular, como também nominá-las. A segunda reproduz o mundo exterior a partir dos conhecimentos anteriores.

Enfim, a Teoria das Representações Sociais, tem um papel importante ao ancorar e possibilitar a análise das práticas sociais objetivadas no desenvolvimento desta pesquisa. Nesse sentido, Nascimento-Schulze e Camargo (2000) destacam duas orientações para a caracterização de pesquisas e estudos em Representações Sociais: a primeira é mais direcionada para questões culturais e históricas, visando compreender os processos que geram e mantêm as representações vivas nas interações entre os indivíduos e grupos sociais (adotada neste estudo). A segunda orientação volta-se para as questões estruturais das RS, compartilhadas tanto no nível cognitivo quanto linguístico.

Consciente de que existe representação construída no dia a dia dos servidores do IFRN em as suas práticas laborais, essas representações devem constituir a base fundamental para as descobertas de novas práticas a serem organizadas em torno desses sujeitos. Com isso, o presente estudo tem como objetivo principal analisar as representações dos servidores em relação ao processo de gestão democrática no âmbito do Instituto Federal de Educação, Ciência e Tecnologia do Rio Grande do Norte.

\section{Metodologia}

A presente pesquisa trata de um estudo qualitativo, do tipo exploratório-descritivo, o qual foi realizado no IFRN, circunscrevendo-se os campi de Natal Central, Currais Novos e reitoria. A escolha do universo da pesquisa definiu-se pela necessidade de analisar as políticas de gestão estabelecidas por esse novo modelo, entre a reitoria e os campi Natal Central, por serem os mais antigos da instituição, e Currais Novos, por este último ter sido o primeiro campus da fase de expansão para o interior do Estado.

Como critério de inclusão para participar da pesquisa foram elencados os servidores administrativos e docentes que estivessem exercendo suas atividades, que já tivessem passado 
pelo estágio probatório e aqueles que fizeram parte da construção dos documentos que nortearam a gestão democrática do IFRN.

Nesta pesquisa, participaram 130 sujeitos, os participantes tinham faixa etária entre 23 e 50 anos ou mais. Dos respondentes alcançados, $61 \%$ correspondem ao sexo feminino e $39 \%$ ao sexo masculino. Quanto ao segmento de trabalho, 55\% são professores e $45 \%$ técnicos administrativos. Quanto ao grau de escolaridade, além de todos ter uma graduação superior, destes, $21 \%$ tinham especialização, $43 \%$ tinham mestrado e $23 \%$ doutorado. Em relação ao tempo de vínculo profissional com a Instituição, $6 \%$ tinham menos de três anos, $31 \%$ tinham de 3 a 6 anos, $35 \%$ de 7 a 12 anos, 28\% com mais de 12 anos de vínculo.

A amostra define-se como não probabilística, pois se buscou, aleatoriamente e intencionalmente, pessoas que se dispusessem a participar no preenchimento do formulário enviado por meio de plataforma digital.

Para não deixar dúvidas quanto a significância da amostra para o presente estudo, esta foi calculada no pacote estatístico G Power 3.1. Trata-se de um software destinado ao cálculo do poder estatístico (isto é, o teste de hipótese), tendo como base, não apenas o ' $n$ ' necessário para a pesquisa, mas, também, o tipo de cálculo a ser realizado (Faul, Erdfelder, Lang, \& Buchner, 2007).

Para a coleta de dados deste estudo, considerou-se uma probabilidade de $95 \%$ ( $\mathrm{p}<0,05)$, magnitude do efeito amostral $(r \geq 0,30)$ e um padrão de poder hipotético $(\pi \geq 0,80)$. A partir desses critérios, a amostra em questão ( $\mathrm{N}=130$ sujeitos) revelou-se suficiente (tendo como indicadores: $\mathrm{t} \geq 1,98 ; \pi \geq 0,99 ; \mathrm{p}<0,001)$.

Utilizou-se como instrumento para a coleta de dados uma Entrevista Estruturada, sendo os dados analisados por meio da Análise de Conteúdo de Bardin (2008). A análise ocorreu em três etapas: 1) a pré-análise, com uma leitura flutuante; 2) a exploração do material, que é a construção das operações de codificação; 3) refere-se à interpretação do material, convergindo para os objetivos do estudo, especificamente, as ancoragens e objetivações das representações dos sujeitos.

Todos os procedimentos adotados nesta pesquisa seguiram as orientações previstas na Resolução 196/96 do CNS e na Resolução 016/2000 do Conselho Federal de Psicologia (CNS, 1996; Anpepp, 2000), sendo o estudo aprovado pelo Comitê de Ética, por meio do Parecer Consubstanciado $\mathrm{n}^{\mathrm{o}} 1.844 .591$ de 1/12/2016. 


\section{Apresentação e Análise dos Resultados}

Com base na análise dos dados apreendidos, o conhecimento elaborado pelos servidores foi classificado em três categorias: "Documento versus Prática", "Representação da Gestão Democrática dentro do IFRN", e "Participação dos Servidores na Gestão Macro do IFRN", distribuídas em doze subcategorias.

A primeira categoria "Documento versus Prática" ancorou-se em três subcategorias há relação entre teoria e prática (43\%), não há relação entre teoria e prática (42\%) e desconhecimento da relação entre teoria e prática $(15 \%)$.

Segundo o IFRN (2012, p. 16), “o documento é uma síntese do pensamento institucional e resultado do planejamento coletivo e participativo." Assim, diante dos resultados, pode-se inferir que na subcategoria Há relação entre a teoria e prática, segundo o PDI/IFRN (20142018), na sua construção, buscou-se envolver todos os funcionários que fazem parte da Instituição a fim de construir coletivamente um documento democrático. Assim, para os participantes dessa subcategoria, o que está proposto nos documentos oficiais corrobora com as práticas do dia a dia dentro da Instituição, objetivadas na fala abaixo:

"Na imensa maioria, particularmente no tocante a organização didática".

"Não percebo nenhuma diferença".

"Sempre se planeja o ideal, mas na operacionalização nem sempre é possível..."

$\mathrm{Na}$ subcategoria Não há relação entre documento e prática, os participantes não corroboram com o que aponta o IFRN (2012, p. 53) ao afirmar categoricamente não serem possíveis práticas educativas sem a busca da "superação da dicotomia teoria-prática", sendo um compromisso assumido nos documentos oficiais na sua dimensão global. Percebe-se que existe uma considerável parcela que não representam essa relação, objetivadas na fala abaixo:

"Existe um distanciamento entre a teoria posta nos documentos e a prática do dia a dia"

"O avanço foi só na discussão teórica"

"Não se consegui ainda da forma que está escrita"

Na última subcategoria Desconhecimento da relação entre teoria e prática, o que consta nos documentos oficiais não retrata as representações dos participantes, mostrando uma inadequação entre as práticas e os documentos, objetivadas na fala abaixo:

"Não tenho conhecimento"

"Não comparei"

"Não sei" 
Essas duas últimas subcategorias representam uma parcela significativa dos participantes do estudo, demonstrando um desconhecimento das atividades inerentes à objetivação dos respondentes em pleno exercício de suas funções.

Segundo Fernandes (2015), para melhor entender o comportamento é necessário entender o que o sujeito traz de experiências vividas. Com as ancoragens apresentadas pelos participantes foi possível responder um dos objetivos da pesquisa, o de entender o processo de gestão democrática posto nos documentos oficiais do IFRN e a prática do dia a dia dentro da Instituição.

As representações sociais dos servidores sobre a segunda categoria "Representação da Gestão Democrática dentro do IFRN", foram ancoradas em cinco subcategorias, apontando para 28\% a gestão democrática é inexistente, 3,0\% apontam para decisões colegiadas, $29 \%$ afirmam que a teoria é sem prática, $19 \%$ que a gestão é parcialmente democrática e $21 \%$ que a gestão é democrática.

De acordo com o PPP, IFRN (2012) em todos os seus capítulos defende a gestão democrática. É possível perceber na fala da maioria dos respondentes a necessidade de se buscar a efetivação dessas práticas. Segundo o IFRN (2012, p. 18), "Trata-se de uma (re)construção identitária que, necessariamente, demandou ser balizada pelos princípios da gestão democrática da participação.” A partir dessa afirmação, apresentam-se as subcategorias.

A primeira subcategoria, Inexistente, constata-se a partir das ancoragens dos participantes, visto que se percebe um nível de fragilidade evidenciada na afirmação dos documentos da Instituição e nos caminhos traçados por eles, com referência à gestão democrática. Segundo Barcelar (1997), para implantar a gestão democrática em uma Instituição de ensino seria necessário, antes de tudo, saber avaliar, para que posturas inadequadas não apareçam nessa construção, o que por muitas vezes requer um novo olhar de todos. Pode se verificar nas falas abaixo:

\footnotetext{
"Nenhuma"

“...não há gestão democrática"

Não me expresso em relação a esse tema"
}

Sobre a segunda subcategoria, ancorada como Decisões Colegiadas, é importante destacar que o IFRN (2014-2018, p. 136) preconiza que "a administração geral do IFRN é feita por seus colegiados deliberativos". Nessa direção foi possível extrair nas entrevistas a ancoragem que os sujeitos têm dos conselhos, reconhecendo seu caráter democrático e 
ressaltando sua importância na construção da Instituição, afirmando ser uma cultura Institucional.

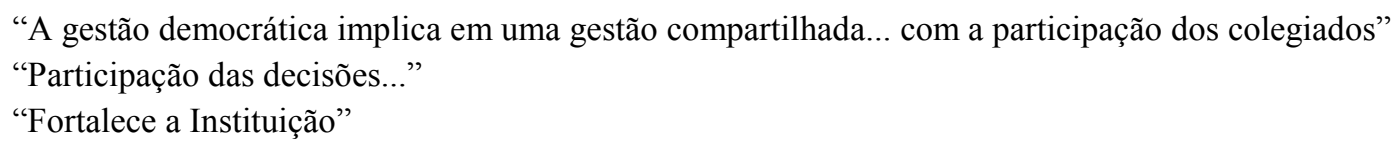

A terceira subcategoria, Teoria sem prática, apresenta-se com o maior percentual no que diz respeito à execução das atividades dos respondentes no processo de gestão democrática. As representações dos participantes apontam para a complexidade da Instituição e a necessidade de elaborar e estabelecer novos parâmetros internos que permitam novas discussões nas bases teóricas e práticas da gestão democrática.

Sob esse prisma há obstáculos e fragilidades dos vínculos entre teoria e prática apontadas pelos respondentes no âmbito da Instituição, considerando-se a complexidade da subcategoria. Os reflexos das falas demonstram um desalento, regado por uma aflição em assegurar a gestão democrática, visando à construção de um espaço onde a teoria se reflita na prática. Isso pode ser observado nos relatos dos servidores abaixo:

Não vi nem participei de qualquer palestra ou debates sobre gestão democrática participativa"

"...o avanço foi só no discurso teórico..."

"Não existe essa gestão democrática dentro do IFRN"

A quarta subcategoria foi ancorada como Gestão democrática parcial; esta teve como base de orientação conceitual a "gestão democrática como concepção", uma vez que ao "adotála institucionalmente, percebe-se a necessidade de avançar na superação da cultura autoritária e centralizadora" (IFRN (2012, p. 57). Assim, é possível identificar nas falas dos participantes uma esperança de uma gestão democrática. As representações também apontam o desejo de avançar nas tomadas de decisões, onde todos possam participar.

Nessa perspectiva, os participantes envolvidos na pesquisa carregam o desejo de buscar uma forma de colaborar coletivamente com as decisões, afirmando que a Instituição é um espaço de conflitos e interesses diversos, que para Melo et al. (2000) reflete sobre o termo de compartilhar a gestão, objetivadas nas falas dos sujeitos abaixo:

\footnotetext{
“...Tem uma gestão parcialmente democrática...”

"...processo em construção"

“...não vejo como uma realidade plena"
}

A quinta subcategoria, A gestão é democrática, retrata a Instituição por meio de seu Projeto Político Pedagógico (2014-2018, p. 65) que apresenta como princípio “a gestão democrática obedecendo à participação coletiva nas instâncias deliberativas”, corroborando 
com o que aponta o PPP/IFRN uma parcela dos participantes representaram essa concepção reafirmando essa prática dentro da Instituição e a importância da gestão democrática nesta, afirmada por Santos e Almeida (2005) como um trabalho coletivo que exige a participação de todos. Portanto, a gestão democrática se consolida como um compromisso coletivo dentro da Instituição, refletida nas falas dos atores sociais abaixo:

\footnotetext{
"Muito forte e atuante"

"Quando escuta nossas propostas"

"Participação dos servidores"
}

A última categoria refere-se à "Participação dos servidores na gestão macro", objetivadas por meio de quatro subcategorias. Apontam que, para $22 \%$ a participação é direta, $27 \%$ é parcial, $29 \%$ afirmam não existir participação e $22 \%$ se sentem representados através dos conselhos existentes na Instituição.

$\mathrm{Na}$ subcategoria a participação é direta, as falas de uma parcela dos participantes afirmam que existe uma participação nas decisões da gestão, contribuindo, dessa forma, com a consolidação das práticas democráticas. Para Moscovici (1996) a participação dos indivíduos não aparece apenas como processador do poder de informação, mas como participantes ativos. Assim é possível compreender como os participantes representam essa participação a partir das teias de relações construídas e desconstruídas de acordo com as demandas que se apresentam nas dependências do IFRN, que é um dos pilares do novo formato administrativo da Instituição, segundo o PPP do IFRN (2012).

\footnotetext{
"...os servidores participam periodicamente das avaliações..."

"Aceitando sugestões"

"Os servidores participam sempre..."
}

A segunda subcategoria objetivou em Parcialmente. O PPP do IFRN (2012, p. 67) traz a participação como uma necessidade nas decisões a serem tomadas, buscando assim, um "compromisso coletivo", que entra em conflito com essa parcialidade representadas pelos participantes através das respostas da subcategoria em questão.

É preciso, portanto, analisar de forma mais profunda o que está implícita na objetivação dos participantes quanto ao nível de participação e decisão. Para Brito e Holanda (2009), os trabalhadores têm um papel fundamental nas tarefas e ações na construção de uma efetiva participação e dentro do seu espaço de vivência. Corroborando com o pensamento das autoras, os participantes também abordam que no processo de participação as ações são fundamentais, objetivadas nas falas abaixo:

“...em alguns projetos vê-se participação" 
“...a Instituição está muito grande e a estrutura democrática não acompanha...”

“...os servidores precisam conhecer mais...”

A terceira subcategoria, Não existe participação, aguça uma reflexão em profundidade do papel que cada participante desempenha dentro da Instituição em relação à participação. Segundo Luck (2006), a importância da participação não está diretamente relacionado somente a produção ou o estado de satisfação do trabalhador, mas sim, à institucionalização, motivação e manutenção dos direitos democráticos. Com essa reflexão do autor é possível identificar a falta de envolvimento dos participantes, uma vez que a participação é um processo que se constrói coletivamente.

\footnotetext{
"Não sei”

"...a Reitoria concentra tudo"

"Não participo"
}

A última subcategoria objetivada como participação através dos conselhos, representa uma parcela importante dos entrevistados que mostra a importância dos conselhos em um processo de gestão democrática. Brito e Holanda (2009) destacam que os conselhos são uma chance de a sociedade ter um maior controle social, possibilitando a inclusão de novas pessoas no processo de participação.

\footnotetext{
“...participando nos Conselhos"

"...em todos os Conselhos existe representação"

"Apenas representativamente"
}

Nesse universo, a alternância dos conselheiros facilita a compreensão do processo democrático preconizador de uma forma diversificada do entendimento desses processos pelos respondentes.

O ser humano é inacabável, no caso dos servidores da Instituição são pessoas em constantes transformações, podendo enveredar por caminhos diversos. Para o PPP (p. 37), "não é possível reduzir o humano a um só princípio... quer seja o inconsciente, o consciente, a matéria, o espírito, a racionalidade ou irracionalidade". Então, os participantes desta pesquisa são entendidos com seres em construção.

\section{Considerações Finais}

Nos dez últimos anos, o Instituto Federal de Educação Ciência e Tecnologia do Rio Grande do Norte vem passando por um processo de expansão, que tem como foco principal 
atender a demanda da educação profissional, sustentada nos pilares da participação e gestão democrática, inspirados em uma ideologia compartilhada por meio de ações políticas (Ferreira, 2004).

Para se efetivar uma gestão democrática participativa é preciso reconhecer a configuração de uma Instituição escolar como uma organização. No caso do IFRN, os campi pertencem a uma estrutura descentralizada, com autonomia administrativa, financeira e pedagógica, com assessoria de uma reitoria. A partir do desenvolvimento desses campi, é provável que ocorra uma sustentabilidade político-administrativa com uma gestão democrática participativa, exigindo atuações coletivas, envolvimento dos atores sociais da própria instituição de ensino, possibilitando o atendimento às expectativas dos envolvidos nesse processo de democracia.

As representações objetivadas neste estudo ancoram a existência de uma estrutura organizacional sistêmica, com ela uma série de documentos concentram todas as diretrizes e princípios institucionais. Se por um lado esses documentos garantem o direito dos servidores de participarem diretamente das decisões institucionais, por outro lado, a maioria dos participantes do estudo não reconhece esse poder dentro da Instituição. Vale destacar que, no processo da pesquisa, os participantes encontravam-se em suas atividades laborais dentro da Instituição

No direcionamento da representação que os participantes têm com relação às atividades planejadas, é perceptível o aspecto negativo objetivado nas respostas das subcategorias "inexistente" e "teoria sem prática". O não reconhecimento da gestão democrática pelos respondentes deixa claro que novos caminhos deverão ser percorridos a partir de um novo olhar à frente dos documentos oficiais, observando, percebendo e refletindo sobre a invisibilidade de algumas situações do cotidiano laboral.

As representações objetivadas na pesquisa são apresentadas como uma complexa teia vivenciada pelos respondentes. Um destaque positivo no estudo ocorreu através do reconhecimento dos participantes em relação à importância que os Conselhos desempenham dentro da Instituição, como espaço de participação e representatividade democrática, ainda que isso não garanta o poder de decisão da maioria, segundo os participantes da pesquisa.

Assim, ancorada em uma visão mais ampla de como executar as tarefas, conclui-se que há uma sinalização na direção essencial de adequar as práticas ao que está escrito nos documentos oficiais, norteando e sustentando a gestão, concordando assim com Jodelet (2001), quando afirma a importância de as representações na vida cotidiana, pois circulam nas discussões cristalizadas em condutas. 
Constatou-se também que existe um distanciamento das políticas macro com as representações dos participantes, objetivadas nas vivências do cotidiano, uma vez que a participação dos servidores se apresenta como oportunidade de ampliação e controle do próprio caminho dentro da Instituição, necessitando de estratégias que possibilitem aos servidores participarem diretamente no processo de construção e decisão dentro da Instituição, tornandose imprescindível estabelecer novas regras cuja rotatividade de informações seja permitida, e atenda aos participantes enquadrados no perfil de não reconhecimento da participação, seja ela direta, parcial e, principalmente, os que afirmam não existir participação.

Com base nas ancoragens concebidas como um processo que transforma algo estranho e desafiador em algo corriqueiro (Moscovici, 2003) dos participantes, fazendo uma analogia com o que está instituído nos documentos oficiais da Instituição, faz-se necessária uma maior divulgação das normas estabelecidas nesses documentos, e, desse modo, criar uma cultura organizacional em que todos conheçam e participem de forma mais colaborativa na construção e aplicação dessas normas norteadoras de toda a trajetória das atividades administrativas, financeiras e acadêmicas da Instituição.

Conforme todo processo de participação democrática, e para os participantes não é diferente, ocorre um movimento de avanço e retrocesso, e a consciência é o reconhecimento desse processo, viabilizando a prática de participação, proporcionando um espaço de luta, debates e, sobretudo, de aceitação dos conflitos que, poderão ou não, impulsionar novos posicionamentos na direção de um novo olhar sobre o que se faz e o que se gostaria de fazer dentro do seu espaço de atividades.

Para os participantes da pesquisa, existe um longo caminho a ser percorrido dentro da Instituição para que a participação possa ser de fato efetivada de acordo com o que sinalizam os documentos institucionais.

Com esse pensamento, e consolidado pelas representações sociais que emergiram no estudo, é necessário adotar na Instituição uma participação mais direta e crítica em todos os ambientes de relações, tanto nas tomadas de decisões, quanto na construção dos documentos oficiais que se configuram nas políticas e ações dentro do ambiente institucional.

\section{Referências}

Bardin, L. (2008). Análise de conteúdo. São Paulo: Edições 70. 
Barcelar, I. V. (1997). Escola, descentralização e autonomia. Revista de Administração Escolar, $1(1), 27-37$.

Bordenave, J. E. D. (1983). O que é participação. São Paulo: Brasiliense.

Brasil, Constituição (1988). Constituição da República Federativa do Brasil. Brasília, DF: Senado Federal.

. (1996). Ministério da Educação. Lei de Diretrizes e Bases da Educação Nacional. Lei $n^{\circ}$ 9.394, Brasília, DF.

. (2008). Lei $n^{o}$. 11.892, de 29 de dezembro de 2008. Institui a Rede Federal de Educação Profissional, Científica e Tecnológica, cria os Institutos Federais de 88 Educação, Ciência e Tecnologia, e dá outras providências. Diário Oficial da União, 30 dez. 2008, Seção 1, p. 1. Brasília, DF.

Brito, L. M. \& Holanda, F. C. (2009). Gestão participativa na educação. Pretexto, 10 (1), 2948.

Dourado, L F. (2007). Políticas e gestão da educação básica no Brasil: Limites e perspectivas Educ.Soc., 28(100), 921-946. Recuperado em outubro, 2017, de HTTP:// www.cedes.unicamp.br.

Gramsci, A. (2001). Cadernos do cárcere. Os intelectuais. O princípio educativo. Jornalismo. (2a ed.). Rio de Janeiro: Civilização Brasileira.

Faul, F., Erdfelder, E., Lang, A. G., \& Buchner, A. (2007). G* Power 3: A flexible statistical power analysis program for the social, behavioral, and biomedical sciences. Behavior research methods, 39(2), 175-191.

Ferreira, N. S. C. (2004). Gestão democrática da educação: ressignificando conceitos e possibilidades. In: Ferreira, N. S. C. \& Aguiar, M. A. S. (org.). Gestão da educação: impasses, perspectiva e compromissos. São Paulo: Cortez. 
Fernandes, F. C. M. (2015). Racionalidades e ambiguidades da organização Instituto Federal: o caso do Rio Grande do Norte. Braga: Universidade do Minho - Instituto de Educação.

França, M. (2004). Gestão educacional nos anos 90: um estudo da descentralização financeira. Tese de doutorado em Educação, Universidade Federal do Rio Grande do Norte - UFRN, Natal.

Gatti J, D. A. (2002). A história das instituições educacionais: inovações paradigmáticas e temáticas. In: Araújo, J. C, S. \& Gatti J. D. A. (Org). Novos temas da educação brasileira; instituições escolares na imprensa, (pp. 3-24) Campinas: Autores associados, Edufu.

Gracindo, R.V. (2009). O gestor escolar e as demandas da gestão democrática. Exigências, práticas, perfil e formação. Revista Retratos da Escola, Brasília, 3(4), 135-147. Disponível em: 〈http//www.esforce.org.br>.

IFRN -Instituto Federal de Educação, Ciência e Tecnologia do Rio Grande do Norte (2010). Regimento Geral do IFRN. Natal-RN.

_ (2012). Projeto Político Pedagógico do IFRN. Natal-RN. (2014). Plano de Desenvolvimento Institucional do IFRN. Natal-RN.

Jodelet, D. (2001). Representação social: um domínio em expansão. In: Jodelet, D. As representações sociais, (pp. 17-44). Rio de Janeiro: UERJ.

Jovchelovitch, S. (2001). Cultura e pesquisa. Representações sociais: saberes sociais e polifasia cognitiva, (pp.1-56). EduCadernos, Caderno 2.

Luck, H. (2006). Concepções e processos democráticos de gestão educacional. Petrópolis: Vozes. . (2004). A escola participativa: o trabalho do gestor escolar (6a ed). Rio de Janeiro: DP\&A. 
(2000). Perspectivas da gestão escolar e implicações quanto à formação de seus gestores. Em Aberto, 17(72), 22.

Lima, L. (2000). Escola como organização educativa. São Paulo: Cortez.

Macedo, G. (2000). A universidade dialética: Consciência, liberdade e saber (4a ed.). Ed. Edufal, Editora da Universidade.

Moscovici, S. (1978). Comunicação apresentada ao Colóquio: Representações Sociais (pp. 810). Paris, EHESS.

. (1996). La Psychnalyse, son, image et son public. Paris: Presses Universitaires de France.

. (2003). Representações sociais: investigações em Psicologia Social. Petrópolis- RJ: Vozes.

Melo, M. T. L. et al. (2000). Gestão da educação: impasses, perspectiva e compromissos. São Paulo: Cortez.

Nascimento-Schulze, C. \& Camargo, B. (2000) Psicologia social, representações sociais e métodos. Temas em Psicologia, 8 (3), 287-299.

Paro, V. H. (2012). Administração Escolar: introdução crítica (17a ed). São Paulo: Editora Cortez.

Veiga, I. P. A. (1997). Projeto político pedagógico - Uma construção possível. Campinas, SP: Papirus.

Santos, M. de F. \& Almeida, L. M. (2005). Diálogo com a teoria das representações sociais. Universitária: UFPE. 
Estevam, I. D., Batista, P. F. A., Formiga, N. S. (2018)

Santos, I.M. \& Prado, E.C. (2014). A gestão da educação e o programa mais educação. Educação em Perspectiva, 5(1), 156-173.

Souza, A. R. de. (2009). Explorando e construindo um conceito de gestão escolar democrática. Educação em revista. 25(3), 123-140.

Trindade, Z. A.; Santos, M. F. S.; \& Almeida, A.M. O. (2014). Ancoragem: notas sobre consensos e dissensos. Em: Oliveira, A. M. el al. (Org). Teoria das Representações Sociais:50 anos. Brasília: Techopolitik. 